\title{
Bibliography
}

\author{
Agarwal, R.P.(1965). An extension of Meijer's G-function. Proc. Nat. \\ Inst. Sci. India Part A 31, 536-546.
}

Aizenberg,L.A. and Yuzakov, A.P.(1979). Integral representations and residues in multidimensional complex analysis. Nauka. Novosibirsk. (Russian).

Anguino M.E.F. de.(1975). On an integral transform involving a kernel of Mellin-Barnes type integral. Kyungpook Math. J. 15, 175-181.

Appel1, P.and Kampe de Feriet, J. (1926). Fonctions Hypergeometriqueset Hyperspheriques; Polynomes d'Hermite. Gauthier-Villars, Paris.

Bora, S.L. and Kalla, S.L. (1970). Some results involving generalized function of two variables. Kyungpook Math. J. 10, 133-140.

Bozhinov, N. (1988). Convolutional representations of commutants and multipliers. Sofia: Publ. House Bulg. Acad. Science.

Braaksma, B.L.J. (1963). Asymptotic expansions and analytic continuations for a class of Barnes-integrals.Compositio Math. 15, 339-341.

Brychkov, Yu.A., Glaeske,H.-J. and Marichev,O.I. (1983). Factorization of integral transformations of convolution type. Itogi Nauki $i$ Techniki. Math. Anal. VINITI. 21, 3-41. (Russian); English transl.in J. Soviet Math. 1985, 3.

Brychkov, Yu.A., Glaeske,H.-J., Prudnikov, A.P. and Vu Kim Tuan. (1992). Multidimensional integral transforms. Gordon and Breach, New York, London, Paris, Montreux, Tokyo. 
Burchnall, J.L. and Chaundy, T.W. (1940). Expansions of Appell's double hypergeometric functions. Quart. J. Math. Oxford Ser. 11, 249-270.

Burchnall, J.L. and Chaundy, T.W. (1941). Expansions of Appell's double hypergeometric functions (II). Quart. J. Math. Oxford Ser.12, 112-128.

Buschman, R.G. (1977). H-functions of two variables, II. Jnanabha. 20, 107-118.

Buschman, R.G.(1978). H-functions of two variables, I. Indian J.Math. $20,105-116$.

Buschman, R.G. (1979a).H-functions of two variables, III.Pure Appl. Math. Sci. 9, 13-18.

Buschman, R.G. (1979b). H-functions of N variables. Ranchi Univ. Math. J. 10, 81-88.

Buschman, R.G. (1981). H-function transformation chains. J. Indian Acad. Math. 3, N 2, 1-5.

Buschman, R.G. (1981a). Hindden reducibilities of H-functions of two variables. Indian J. Pure Appl. Math. 12, 1448-1451.

Buschman, R.G. (1981b). Reduction formulas for Appell functions for special values of the variables. Indian J. Pure Appl. Math. 12, 1452-1453.

Buschman, R.G. (1982a). Analytic domains for multivariable H-functions. Pure Appl. Math. Sci. 16, 23-27.

Buschman, R.G. (1982b). Factorization of H-functions. J. Indian Acad. Math. 4, 69-73. 
Buschman, R.G. (1987). A theorem for simple contiguous function relations. Ganita $1, \mathrm{~N}^{1-2}, 25-28$.

Buschman, R.G. (1987a). Contiguous relations for Appell functions. Indian J. Math. 29, $\mathrm{N} 2,165-171$.

Buschman, R.G. (1987b). Contiguous relations for Meijer's G-function. Indian J. Pure Appl. Math. 18, N 6, 536-547.

Buschman, R.G. (1990). Simple contiguous function relations for functions defined by Mellin-Barnes integrals. Indian J. Math. 32, $\mathrm{N} 1$, 25-32.

Buschman, R.G. and Gupta, K.C.(1975). Contiguous relations for the $\mathrm{H}$-function of two variables. Indian J. Pure Appl. Math. 6, N 12, 1416-1421.

Buschman, R.G., Koul, C.L. and Gupta, K.C. (1977). Convolution integral equations involving the H-function of two variables. Glasnik Matematicki 12, N 32, 61-66.

Buschman, R.G. and Srivastava, H.M. (1975). Inversion formulas for the integral transformation with the H-function as kernel. Indian $J$. Pure Appl. Math. 6, N 6, 583-590.

Buschman, R.G. and Srivastava, H.M. (1986). Convergence regions for some multiple Mellin-Barnes contour integrals representing generalized hypergeometric functions. Internat. J. Math. Ed. Sci. Tech. 17, 605-609.

Chaturvedi, K.K. and Goyal, A.N. (1972). A ${ }^{*}$-function. Indian J. Pure Appl. Math. 3, 357-360.

Cih, A.K.(1988). The multidimensional residues and their applications. Nauka. Novosibirsk. (Russian).

Davis, B. (1978). Integral transforms and their applications. Berlin. New York: Springer-Verlag. 
Dimovski, I.H.(1974). A transform approach to operational calculus for the general Bessel-type differential operator. Computers rendus Acad. Bulg. Sci. 27, N 2, 155-158.

Dimovski, I.H. (1981). Convolution representation of the commutant of Gel'fond-Leont'ev integration operator. C. R. Acad. Bulg. Sci. 34, N 12, 1643-1646.

Dimovski, I.H.(1982). Convolutional calculus. Sofia: Publ.House Bulg. Acad. Sci., 2. (Second ed.:Dorbrecht. Boston and London: Kluwer Acad. Publ., East Europ. Ser. 1990, 43. ).

Dimovski, I.H. and Kiryakova, V.S. (1983). Convolution and commutant of Gel'fond-Leont'iev operator of integration. In Proc. Intern. Conf. Constr. Function Theory'81 (Varna, 1981), Sofia: Publ. House Bulg. Acad. Sci., 288-294.

Dimovski, I.H. and Kiryakova, V.S.(1984). Convolutions and differential property of Borel-Dzrbasjan transform. In Proc. Intern. Conf. Complex Analysis and Appl.'81 (Varna, 1981), Sofia: Publ. House Bulg. Acad. Sci., 148-156.

Dimovski, I.H. and Kiryakova, V.S.(1985). Transmutations, convolutions and fractional powers of Bessel-type operators via Meijer's G-function. In Proc. Intern. Conf. Complex Analysis and Appl.' 83 (Varna, 1983), Sofia: Publ. House Bulg. Acad. Sci., 45-66.

Dimovski, I.H. and Kalla, S.L.(1988).Explicit convolution for Hermite transform. Math. Japonica. 33, N 3, 345-351.

Ditkin, V.A. and Prudnikov, A.P.(1958). Operational calculus of two variables and its applications. Fizmatgiz. Moscow. (Russian).

Ditkin, V.A. and Prudnikov, A.P. (1965). Integral transformations and operational calculus. Pergamon Press. 
Ditkin, V.A. and Prudnikov, A.P. (1967). Integral transforms. Itogi Nauki i Techniki. Math. Anal. VINITI. 7-82. (Russian); English transl.in Progress in Math. 1969, 4.

Dixon, A.L. and Ferrar, W.L. (1936). A class of discontinuous integrals. Quart. J. Math. Oxford Ser. 7, 81-96.

Doetsch, G.(1956). Handbuch der Laplace-Transformation. Basel und Stuttgart: Birhäuser Verlag.

Dzrbasjan, M.M.(1966). Integral transforms and representations of the functions in the complex domain. Moscow. Nauka. (Russian).

Embrechts, P. and Omey, E. (1988). An Abelian theorem for a general class of Mellin type integral transforms. J. Math. Anal. Appl. 132, N 1, $138-145$.

Erdelyi, A., Magnus, W., Oberhettinger, F. and Tricomi, F.G. (1953). Higher. Transcendental Functions, Vols I and II. McGraw-Hill, New York.

Exton,H.(1976). Multiple Hypergeometric Functions and Applications. Ellis Horwood Ltd., Chichester, New York, Toronto.

Exton, H. (1978). Handbook of Hypergeometric Integrals. Ellis Horwood Ltd., Chichester, New York, Toronto.

Fedorjuk, M.V.(1986). Integral transforms. Itogi Nauki i Techniki. VINITI 13, 211-253. (Russian).

Flensted-Jensen, M. and Koornwinder, T. (1973). The convolution structure for Jacobi function expansions. Ark. Mat. 11, 245-262.

Fox,C. (1961). The G- and H-functions as symmetrical Fourier kernels. Tran. Amer. Math. Soc. 98, 395-429. 
Glaeske, H.-J.(1981). Die Laguerre-Pinney-Transformation. Aequat. Math. 22, 73-85.

Glaeske, H.-J.(1982). On a class of integral transformations. Wiss. Ztsch. F.-Schiller-Univ. Jena. Math.-Nat. 31, 579-586.

Glaeske, H.-J.(1986). On the Wiener-Laguerre transformation. Rev. Tec. Ing. Univ. Zulia. 9, 27-35.

Glaeske, H.-J. (1987). Operational properties of a generalized Hermite transformation. Aequat. Math. 32, 155-170.

Glaeske, H.-J. and Heß, A. (1986). A convolution connected with the Kontorovich-Lebedev transform. Math. Z. 193, 67-78.

Glaeske, H.-J. and Heß, A. (1987). On the convolution theorem of the Mehler-Fock-Transform for a class of generalized functions (I). Math. Nachr. 131, 107-117.

Glaeske, H.-J. and Heß, A. (1988). On the convolution theorem of the Mehler-Fock-Transform for a class of generalized functions (II). Math. Nachr. 136, 119-129.

Goldberg, R.R.(1957). Convolution transforms of almost periodic functions. Riv. Mat. Univ. Parma 8, 307-312.

Goldberg, R.R.(1961). Spaces of convolutions and fractional integrals. J. Math. Anal. Appl. 3, 336-343.

Goyal, S.P. (1971). A generalized function of two variables I. Univ. Studies Math. N 1, 37-46.

Goyal, S.P. (1975). The H-function of two variables. Kyungpook Math. J. 15, 117-131.

Gupta, K.C. and Mittal, P.K.(1970). The H-function transform, J. Austr. Math. Soc. 11, 142-148. 
Gupta, K.C. and Mittal, P.K. (1971). The H-function transform, II. J. Austr. Math. Soc. 12, 444-450.

Hirchman, I.I. and Widder, D.W. (1955). The convolution transform. Princeton, New Jersy: Univ. Press.

Horn, J.(1889). Ueber die convergenz der hypergeometrichen Reihenzweier und dreuer veranderlichen. Math. Ann. 34, 544-600.

Horn, J. (1931). Hypergeometriche funktionen zweier veranderlichen. Math. Ann. 105, 381-407.

Joshi, C.M. and Prajapat, M.L. (1977). On some results concerning generalized H-function of two variables. Indian J. Pure Appl.Math. 8, N 1, 103-116.

Kakichev, V.A. (1967). On the convolutions for integral transforms. Izv. Acad. Navuk. BSSR. Ser. Fiz.-Mat. Navuk. N 2, 48-57. (Russian).

Kakichev, V.A. (1990). On the matrix convolution for power series.Izv. Vuzov. Matematika. 2, 53-62. (Russian).

Kalla, S.L. (1969a). Integral operators involving Fox's H-function. Acta Mexicana Cienc. y Tecnol. 3, 117-122.

Kalla, S.L. (1969b). Integral operators involving Fox's H-function. II. Notas Cie. 7, 72-79.

Kalla,S.L. (1972). On the solution of an integral equation involving a kernel of Mellin-Barnes type integral. Kyungpook Math. J. 12, 93-101.

Kapoor, V.K. (1968). On a generalized Stieltjes transform. Proc. Cambridge Philos. Soc. Math. and Phys. Sci. 64, 407-412.

Kapoor, V.K. and Masood, S. (1968). On a generalized L-H transform. Proc. Cambridge Philos. Soc. Math. and Phys. Sci. 64, 399-406. 
Kesarwani, R.N.(1962). The G-functions as unsymmetrical Fourier kernels. I. Proc. Amer. Math. Soc. 13, N 6, 950-959.

Kesarwani, R.N.(1963a). The G-functions as unsymmetrical Fourier kernels. II. Proc. Amer. Math. Soc. 14, N 1, 18-28.

Kesarwani, R.N.(1963b). The G-functions as unsymmetrical Fourier kernels. III. Proc. Amer. Math. Soc. 14, N 1, 271-277.

Kesarwani, R.N.(1965a). The G-functions as kernels in chain transform. Portugal. Math. 24, N 1, 39-45.

Kesarwani, R.N.(1965b). A pair of unsymmetrical Fourier kernels. Trans. Amer. Math. Soc. 115, N 3, 356-359.

Kesarwani, R.N.(1971). On an integral transform involving Gfunction. SIAM J. Appl. Math. 20, 93-98.

Kiryakova, V.S.(1989). Convolutions of Erdelyi-Kober fractional integrals. In Proc. Intern. Conf. Complex Analysis and Appl.'87 (Varna, 1987), Sofia: Publ. House Bulg. Acad. Sci., 273-283.

Kratzel, E.(1965). Eine Veralligemeinerung der Laplace- und Meijer-Transformations. Wiss. Zeitschrift der FSU Jena. Math.-Naturwiss. Reihe. 14, N 5, 369-381.

Luchko, Yu.F and Yakubovich, S.B. (1991). Generating operators and convolutions for some integral transforms. Dokl. Akad. Nauk. BSSR. 35, N 9, 773-776. (Russian).

Luke, Y.L.(1969). The Special Functions and Their Approximations. Vols. I and II. Academic Press. New York.

Marichev, O.I. (1974). One class of integral equations of convolution type with special functions in kernels. Izv. Acad. Navuk. BSSR. Ser. Fiz.-Mat. Navuk, N 1, 126-127 (Russian). 
Marichev, 0.I. (1976). Some integral equations of convolution type with special functions in kernels. IzV. Acad. Navuk. BSSR. Ser. Fiz.-Mat. Navuk, N 6, 119-120 (Russian).

Marichev, 0.I. (1978). Integral operators with special functions in the kernels which generalize integration operators of complex order. Izv. Akad. Navuk BSSR, Ser. Fiz.-Mat. Navuk, N 2, 38-44 (Russian).

Marichev, 0.I. (1983). Handbook of integral transforms of higher transcendental functions, theory and algorithmic tables. Ellis Horwood Ltd., Chichester, New York, Toronto.

Marichev, O.I. (1983a). Asymptotic behavior of functions of hypergeometric type. Vestsi Akad. Navuk BSSR, Ser. Fiz.-Mat. Navuk, N 4 , 18-25 (Russian).

Marichev, 0.I. (1990). The hypergeometric type functions and their some applications to integral and differential equations. Dissertation to the degree of Doctor science (Dr.sc.). Minsk, USSR, Byelorussian State Univ. 373p. (Russian).

Marichev, O.I. and Vu Kim Tuan.(1983a). The definition of the general G-function of two variables, its particular cases and differential equations. Differentzialnye Uravnenija. 19, $\mathrm{N}$ 10, 1797-1799. Dep. in VINITI 11.11.82, N 687-83. 23 pp. (Russian).

Marichev, O.I. and Vu Kim Tuan. (1983b). The problems of definitions and symbols of $\mathrm{G}-$ and H-functions of several variables. Rev. Tecn. Fac. Ingr. Univ. Zulia 6, 144-151.

Marichev, O.I. and Vu Kim Tuan.(1985). Composition structure of some integral transforms of convolution type. Proc. Inst. Appl. Math. of I.N. Vekua. Tbilisi. 1, N 1, 139-142 (Russian).

Marichev, O.I. and Vu Kim Tuan.(1986). Factorization of G-transformation in two classes of functions. In Proc. Intern. Conf. Complex Analysis and Appl.'85 (Varna, 1985), Sofia: Publ. House Bulg. Acad. Sci., 720-735. 
Mathai, A.M. and Saxena, R.K. (1973). Generalized Hypergeometric Functions with Applications in Statistics and Physical Sciences. Springer-Verlag Lecture Notes No.348, Heildelilerg.

Mathai, A.M. and Saxena, R.K. (1978). The H-functions with applications in statistics and other disciplines. New York; London; Sydney: John Wiley.

Meijer, C.S.(1941). Multiplikations theoreme fur die Funktion $\mathrm{G}_{\mathrm{pq}}^{\mathrm{mn}}(\mathrm{z})$. Nederl. Akad. Wetensch. Proc. 44, 1062-1070 = Indag. Math.3, 486-490.

Meijer, C.S. (1946). On the G-function. I, II, III, IV, V, VI, VII, VIII. Proc. Nederl. Akad. Wet. 49, 227-237, 344-356, 457-469, 632-641, $765-772$, 936-943, 1063-1072, 1165-1175.

Mittal, P.K. and Gupta, K.C.(1972). An integral involving generalized function of two variables. Proc. Indian Acad. Sci. Sect. A 75, 117-123.

Mourya, D.P.(1970). Analityc continuations of generalized hypergeometric functions of two variables. Indian J. Pure Appl. Math. 1, 464-469.

Munot, P.C. and Kalla, S.L. (1971) On an extension of generalized function of two variables. Univ. Nac. Tucuman Rev. Ser. A 21, 67-84.

Nguyen Thanh Hai.(1990a). On the convergence of Kampe de Feriet double hypergeometric series. Vestsi Acad. Navuk. BSSR. Ser. Fiz.-Mat. Navuk. N 2,122; Dep. in VINITI 20.04.89, N 2582-V89, 12 pp. (Russian).

Nguyen Thanh Hai.(1990b). On the theory of general Fox's H-function of two variables. Dokl. Akad. Nauk. BSSR. 34, N 4, 297-300 (Russian). 
Nguyen Thanh Hai.(1990c). The functions of hypergeometrictype of two variables and two-dimensional integral transforms. Dissertation to the degree of Candidate (Ph.D.). Minsk USSR,141 pp.; The Abstract of Candidate Dissertation Minsk USSR. Byelorussian StateUniv. Press. 14 pp. (Russian).

Nguyen Thanh Hai.(1992). On the criterion of clarification for the convergence of Mellin-Barnes type double integrals. Vestsi Akad.Navuk. BSSR, Ser. Fiz.-Mat. Navuk. N 1, 25-31. (Russian).

Nguyen Thanh Hai and Buschman, R.G. (1992). Reduction formulas for the $\mathrm{H}$-functions of two variables. J. Indian Acad. Math. (to appear).

Nguyen Thanh Hai, Marichev, O.I. and Buschman, R.G. (1992) Theory of general H-functions of two variables. Rocky Mountain J.Math. (to appear)

Nguyen Thanh Hai, Marichev, O.I. and Srivastava, H.M. (1992). A note on the convergence of certain families of multiple hypergeometric series. J. Math. Anal. Appl. (to appear).

Nguyen Thanh Hai and Yakubovich, S.B. (1990). On certain twodimensional integral transforms of convolution type. Dok1. Akad. Nauk. BSSR. 34, N 5, 396-398 (Russian).

Nieva Pino, M.E. and Kalla, S.L. (1977). Operadores de integracion fractional que involucran la function $\mathrm{H}$ de dos variables $\mathrm{I}$. Acta Mexicana de Ciencia y Tecnol. 11, 31-34.

Nieva Pino, M.E. and Kalla, S.L.(1978). Operadores de integracion fractional que involucran la function $H$ de dos variables II. Acta Mexicana de Ciencia y Tecnol. 12, 32-41.

Nikiforov, A.F. and Uvarov, V.B. (1978). The principles of the theory of special functions. Moscow: Nauka.

Osler, T.J.(1971). Fractional derivatives and Leibniz rule. Amer. Math. Month. 78, N 6, 645-649. 
Osler, T.J.(1972a). An integral analogue of Taylor's series and its use in computing Fourier transforms. Math. Comput. 26, N 118, 449-460.

Osler, T.J.(1972b). The integral analog of the Leibniz rule. Math. Comput.26(120), 903-915.

Pathak, R.S.(1970). Some results involving G- and H-functions. Bul1. Calcutta Math. Soc. 62, 97-106.

Prasad, Y.N. and Singh, A.K. (1981). Infinite integration of certain products associated with Buschman's H-function of two variables. Bull. Math. Soc. Sci Math. R.S. Roumanie, 25, N 73, 65-73.

Prudnikov, A.P., Brychkov, Yu.A. and Marichev O.I. (1986). Integrals and Series. Vol.1: Elementary Functions; Vol.2:Special Functions. Gordon and Breach, New York, London, Paris, Montreux, Tokyo.

Prudnikov, A.P., Brychkov, Yu.A. and Marichev O.I. (1989). Integrals and Series. Vol. 3: More special functions. Gordon and Breach, New York, London, Paris, Montreux, Tokyo.

Prudnikov, A.P., Brychkov, Yu.A. and Marichev O.I.(1989a). The evaluation of integrals and Mellin transform. Itogi Nauki i Techniki. Math. Anal. VINITI. 27, 3-146. (Russian).

Rathie, N. (1989). Reduction formulas for the H-function of two variables. Ganita Sandesh. 1, 42-46.

Reed, I.S. (1944). The Mellin type of double integral. Duke Math. J. $11,565-572$.

Saigo, M., Marichev O.I. and Nguyen Thanh Hai. (1989). Asymptotic representations of Gaussian series ${ }_{2} \mathrm{~F}_{1}$, Clausenian series ${ }_{3} \mathrm{~F}_{2}$ and Appell series $\mathrm{F}_{2}$ and $\mathrm{F}_{3}$ near boundaries of their convergence regions. Fukuoka Univ. Sci. Rep. 19, N 2, 83-90. 
Saigo, M. and Yakubovich, S.B. (1991). On the theory of convolution integrals for G-transforms. Fukuoka Univ. Sci. Rep. 21, N 2, 181-193.

Samko, S.G., Kilbas, A.A. and Marichev 0.I.(1987). Fractional integrals and derivatives and some of their applications. Minsk. Nauka i Tekhnika.

Saxena, R.K. (1966). An inversion formula for a kernel involving a Mellin-Barnes type integral. Proc. Amer. Math. Soc.17, N 4, 771-779.

Saxena, R.K.(1971). An integral associated with generalized H-function and Whittaker functions. Acta Mexicanc Ci. Tecn. 5, 149-154.

Saxena, V.P. (1970). Inversion formulae to certain integral equations involving H-function. Portugal Math. 29(1-2), 31-42.

Shah, M. (1973a). Application of Hermite polynomials for certain properties of Fox's H-function of two variables. Univ.Nac. Tucuman Rev. Ser, A 23, 165-178.

Shah, M. (1973b). On some applications related to Fox's H-function of two variables. Publ. Inst. Math. (Beograd) (N.S.) 16, N 30, 123-133.

Sharma, B.L. (1965). On a generalized function of two variables. I. Ann. Soc. Sci.Bruxeles Ser. I 79, 26-40.

Singh, R. (1970). An inversion formula for Fox H-transform, Proc. Nath. Acad. Sci. India. A 40, 57-64.

Slater, L.J. (1966). Generalized Hypergeometric Functions. Cambridge Univ. Press. London-New York.

Sneddon, I.N. (1951). Fourier transform. New York. McGray Hill.

Sneddon, I.N. (1972). The use of integral transform. New York. McGray Hill. 
Srinivasan, V.(1963). On the generalized Meijer transform. Bull. Acad. Polon. Sci. Ser. A. 11, N 7, 431-440.

Srivastava, H.M. (1972). A class of integral equations involving the H-function as kernel. Nederl. Akad. Wetensch. Proc. Ser. A $75=$ Indag. Math. 34(3), 212-220.

Srivastava, H.M. and Buschman, R.G. (1973). Composition of fractional integral operators involving Fox's H-function. Acta Mexic. Cien. Tecnol. 7, N 1-3, 21-28.

Srivastava, H.M. and Buschman, R.G. (1976). Mellin convolutions and H-function transformations. Rocky Mountain J. Math. 6, 331-343.

Srivastava, H.M. and Buschman, R.G. (1977).Convolution integral equations with special function kernels. New Delhi, Bangalore: Wiley Eastern Ltd.

Srivastava, H.M. and Daoust, M.C. (1972). A note on the convergence of Kampe de Feriet's double hypergeometric series. Math. Nachr. 53, 151-159.

Srivastava, H.M., Gupta, K.C. and Goyal, S.P. (1982). The H-functions of One and Two Variables with Applications. South Asian Publishers. India.

Srivastava, H.M., Koul, C.L. and Raina, R.K. (1985). A class of convolution integral equations. J. Math. Anal. Appl. 108, N 1, 63-72.

Srivastava, H.M. and Karlsson, P.W. (1985). Multiple Gaussian Hypergeometric Series. Ellis Horwood Ltd., Chichester, New York, Toronto.

Ta Li. (1960). A new class of integral transforms. Proc. Amer. Math. Soc. 11, N 2, 290-298. 
Tandon, O.P. (1983). Some predictions. Internat. J. Math. Ed. Sci. Tech. 14, 665-666.

Tanno, Y.(1956). An inversion formula for convolution transforms. Kodai Math. Semin. Repts. 8, N 2, 79-84.

Tanno, Y.(1966). On a class of convolution transforms. Tohoku Math. J. 18, N 2, 156-173.

Tanno, Y.(1967). On a class of convolution transforms II. Tohoku Math. J. 19, N 2, 168-186.

Titchmarsh, E.G. (1937). Introduction to Theory of Fourier Integrals. Oxford Univ. Press, Oxford.

Verma,R.U. (1971). On the H-function of two variables. II. An. Sti. Univ. "Al. I. Cuza" Iasi Sect. I a Mat. (N.S) 17, 103-109.

Vilenkin, N.Ya. (1958). Matrix elements of the indecomposable unitary representations for motions group of the Lobachevski's space and generalized Mehler-Fock transforms. Dokl. AN SSSR. 118, 219-222.

Vu Kim Tuan. (1985). Some questions of the theory and applications of the hypergeometric type functions. Dissertation to the degree of Cand idate (Ph.D.). Minsk, USSR, Byelorussian State Univ. 118p. (Russian).

Vu Kim Tuan.(1986a). Generalized integral transformations of convolution type in some space of functions. In Proc. Intern. Conf. Compl. Anal. and Appl.'85 (Varna, 1985), Sofia: Publ. House Bulg. Acad. Sci., 418-433.

Vu Kim Tuan. (1986b). On the theory of generalized integral trans forms in a certain function space. Dok1. AN SSSR. 286, 521-524; English transl. in Soviet Math. Dokl. 33 (1986), 103-106. 
Vu Kim Tuan. (1986c). On the factorization of the convolution type integral transform in space $\mathrm{L}_{2}^{\Phi}$. Dokl. AN Arm. SSR. 1, 7-10. (Russian).

Vu Kim Tuan.(1987). Integral transforms and their composition structure. Dissertation to the degree of Doctor science (Dr.sc.). Minsk, USSR, Byelorussian State Univ. 322p. (Russian).

Vu Kim Tuan. (1988). Some integral transform of Fourier convolution type. Dok1. AN SSSR. 300, 521-525; English transl. in Soviet Math. Dok1. 37 (1988), 669-673.

Vu Kim Tuan, Marichev, O.I. and Yakubovich, S.B. (1986). Composition structure of integral transformations. Dokl. AN SSSR. 286, 786-790; English transl. in Soviet Math. Dokl. 33 (1986), 166-169.

Watanabe, Y.(1931). Notes on the generalized derivative of Riemann-Liouville and its application to Leibnitz's formula. I and II. Tohoku Math.J. 34, 8-27, 28-41.

Widder, D.W. (1946). The Laplace transform. London. Oxford Univ. Press.

Wiener, N.(1937). The Fourier integral and certain of its applications. New York. Dover Publications.

Yakubovich, S.B.(1987a). General index integral transforms of Kontorovich-Lebedev type and some of their applications. Dissertation to the degree of Candidate (Ph.D.). Minsk, USSR, Byelorussian State Univ. 130p. (Russian).

Yakubovich, S.B.(1987b). On the convolution for KontorovichLebedev transform and its applications to integral equations. Dokl. Akad. Nauk BSSR. 31, N 2, 101-103 (Russian).

Yakubovich, S.B.(1990). On the constructive method of integral convolutions. Dokl. Akad. Nauk. BSSR. 34, N 7, 588-591. (Russian). 
Yakubovich, S.B.(1991). On the integral convolutions of Laplace type for G-transforms. Vestsi Akad. Navuk. BSSR, Ser. Fiz.-Mat. Navuk N 6, 11-16. (Russian).

Yakubovich, S.B.(1992a). On one class of the integral convolutions. Vestsi Akad. Navuk. BSSR, Ser. Fiz.-Mat. Navuk, N 2 (Russian).

Yakubovich S.B. (1992b). About some generalizations of Laplace convolution. Republic's collection "Mathematical Physics and Nonlinear Mechanics", Kiev. (Russian) (to appear).

Yakubovich, S.B. and Luchko, Yu.F.(1991a). Generalizations of the Leibniz rule on the integral convolutions. Dokl. Akad. Nauk. BSSR.35, N 2, 111-115 (Russian).

Yakubovich, S.B. and Luchko, Yu.F.(1991b). The evaluation of integrals and series with respect to indices (parameters) of hypergeometric functions. Proc. Intern. Symp. on Symbolic and Algebraic Comp. ISSAC' 91. Bonn, 15-17 July, 1991, 271-280.

Yakubovich, S.B. and Luchko, Yu.F. (1991c). The generalizations of integral analog of the Leibniz rule on the convolutions. Extracta Mathematicae 6, $\mathrm{N} 2,64-66$.

Yakubovich, S.B. and Nguyen Thanh Hai (1991). Integral convolutions for H-transforms. Izv. Vuzov. Matematika 8, 72-79. (Russian).

Yakubovich, S.B., Nguyen Thanh Hai and Buschman, R.G. (1992). Convolutions for $\mathrm{H}$-function transformations. Indian J. Pure Appl. Math. (to appear).

Yanushauskas, A.I. (1980). Double Series. Nauka. Novosibirsk. (Russian).

Zemanian, A.H. (1965). Generalized integral transforms. New York. McGray Hill. 


\section{This page is intentionally left blank}




\section{Author index}

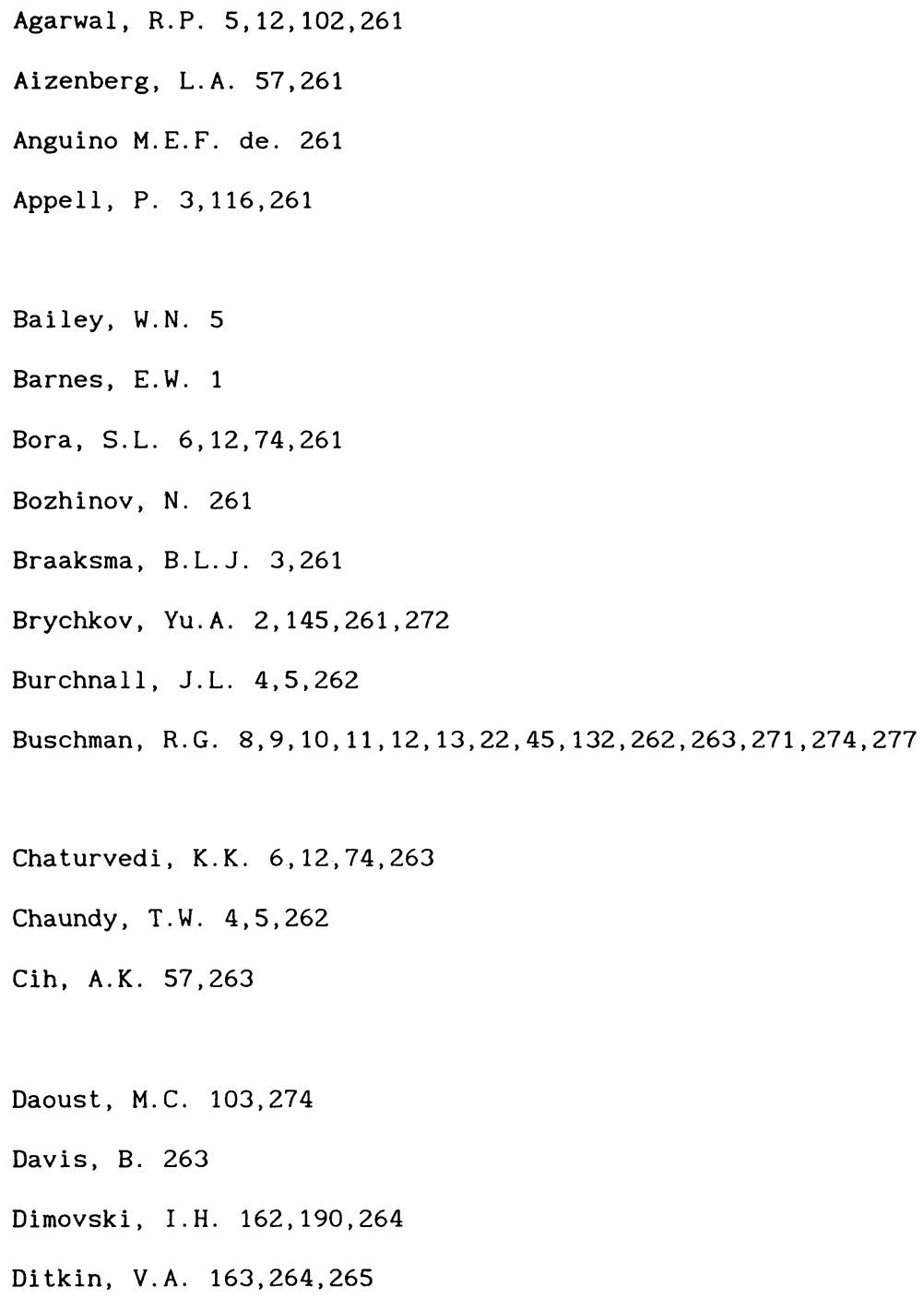


Dixon, A.L. $12,132,265$

Doetsch, G. 265

Dzrbasjan, M.M. 265

Embrechts, P. 265

Erdelyi, A. $1,4,24,41,43,65,84,93,112,113,116,163,217,218,259,265$

Exton, H. 5,265

Fedor juk, M.V. 265

Ferrar, W.L. 12, 132, 265

Flensted-Jensen, M. 162,265

Fox, C. $2,144,265$

Gauss, C.F. 1

Glaeske, H.-J. 145, 162, 261, 266

Goldberg, R.R. 266

Goyal, A.N. 6,12,74,263,266

Goyal, S.P. 3,8,11,266,274

Gupta, K.C. $3,7,8,11,12,71,132,263,266,267,270,274$

Heß, A. 162,266

Hirchman, I. I. 162,267

Horn, J. 3, 59, 267

Joshi, C.M. 267 
Kakichev, V.A. 162,267

Kalla, S.L. $\quad 6,12,74,261,264,267,270,271$

Kampe de Feriet, J. 4,103,113,261

Kapoor, V.K. 144,267

Karlsson, P.W. 5,86,274

Kesarwani, R.N. 144,268

Kilbas, A.A. 220,233,273

Kiryakova, V.S. $190,264,268$

Koornwinder, T. 162,265

Koul, C.L. 263,274

Kratzel, E. 268

Kummer, E.E. 1

Luchko, Yu.F. 233, 268, 277

Luke, Y.L. $1,2,92,268$

Magnus, W. 265

Marichev, O. I. 2, 11, 15, 43, 58, 71, 82, 85, 92, 104,116,119,120,141,144, $217,219,222,230,233,261,268,269,271,272,273,276$

Masood, S. 144,267

Mathai, A.M. 2, 3, 270

Meijer, C.S. 2,270

Mellin, $\mathrm{Hj} .1$

Mittal, P.K. $7,12,71,132,266,267,270$

Mourya, D.P. 270

Munot, P.C. $6,12,74,270$ 
Nguyen Thanh Hai $4,104,116,184,270,271,272,277$

Nieva Pino, M.E. 271

Nikiforov, A.F. 271

Oberhettinger, F. 265

Omey, E. 265

Osler, T.J. 233,271,272

Pathak, R.S. $6,12,74,272$

Pincherle, S. 1

Prajapat, M.L. 267

Prasad, Y.N. 272

Prudnikov, A.P. $2,84,92,93,145,156,163,223,233,250,261,264,265,272$

Raina, R.K. 274

Rathie, N. 272

Reed, I.S. 55,272

Saigo, M. $116,272,273$

Samko, S.G. $220,233,273$

Saxena, R.K. 2, 3,74, 270,273

Saxena, V.P. 4,273

Shah, M. $6,12,74,273$

Sharma, B.L. 5, 12, 102, 273

Singh, A.K. 272

Singh, R. 132,273

Slater, L.J. $1,43,58,68,86,233,273$ 
Sneddon, I.N. $162,225,273$

Srinivasan, V. 274

Srivastava, H.M. $3,5,8,11,22,86,103,104,132,263,271,274$

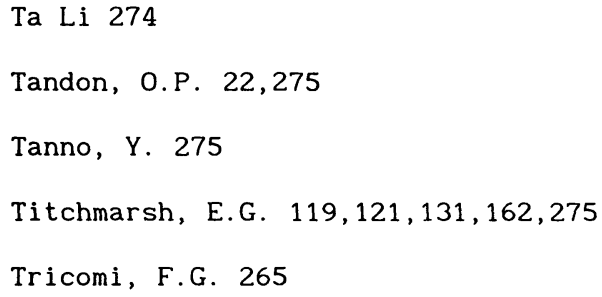

Zemanian, A.H. 277 


\section{This page is intentionally left blank}


Subject index

addition formula for gamma-function 233

additional probability's integral 93

Agarwal's G-function 5

algorithm for the evaluation of index integrals and series 257

Appell functions (series) 42,113,114,115

beta-function $41,168,169$

beta-integral 193

Bessel function $93,98,99$

binomial coefficients 238

Boltz's formula 86

Buschman's H-function of variables 8,9

characteristic of the H-function of two variables 69

Clausenian function 117

composition structure of the G-transform 153

composition structure of the H-transform 140,153

convolution for modified Meijer transform 213

convolution for modified Hankel transform 221

convolution for modified Stieltjes transform 215

convolution for Riemann-Liouville operators 209,210

cos-transform 149

criterion for convergence region of H-integral $13,30,39,40$

contiguous relations 47,48 
degenerate Tricomi function 93, 100

Dixon's summation theorem 234

double hypergeometric type series 57

double Mellin-Barnes type integrals 9,170

double Mellin transform 54

double Mellin transform of the H-function 56

Dougall's formula 234

factorization property 163

factorizations of simplest operators 157

Fox's H-function $3,9,12$

Fourier integrals 131

Fubini theorem 121

G-convolution 198,199

G-function of two variables 5,89

G-transform 142,144

G-transform with Gauss hypergeometric function 155,236

Gauss-Legendre product formula 230

Gauss's hypergeometric series 1

Gaussian summation theorem 68,233

general beta-function 193

general hypergeometric function 1

general integral convolution 170

general Laplace convolution 190-193

generalized binomial coefficients 239 


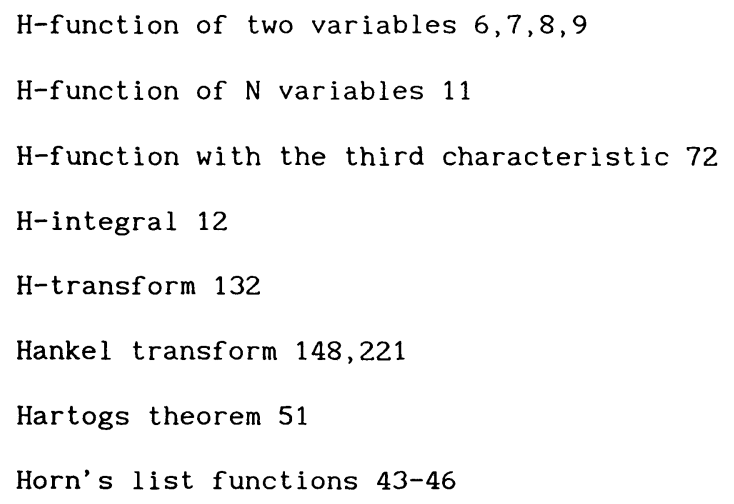


Laplace convolution 163

Lebesgue theorem 242

Leibniz rules $233,236-241,250-252$

Macdonald function 93,99

max-convolution 186,187

Meijer G-function 2

Meijer transform $151,152,213$

Mellin-Barnes type of contour integral 2,3

Mellin correspondences 159-161

Mellin-Parseval formula 119

Mellin transform 119,120

Mellin transform of the H-function 134

Mellin type convolution transform 119

Mittal's and Gupta's H-function 7

modified H-convolution 225

modified Laplace transform 146

$\mathfrak{m}^{-1}(\mathrm{~L})$-space 120

$\mathbb{J}_{c, \gamma}^{-1}(L)-$ space 121

non-complete gamma-function 93,98

operator with Tricomi function and its inverse 235

operator with algebraic function in the kernel 235

operator with generalized Laguerre polynomial 235

Pochhammer symbol 1,103 
reduction formulas $80,83-89$

Riemann-Lebesgue lemma 121

Riemann-Liouville integro-differential operators 147

Saalschütz's summation theorem 234

series representations $57,217,218$

Sharma's S-function 5

sin-transform 149

Slater's notation 43,106

Slater's theorem $58,63,141$

Sonine integral 224

Stieltjes transform 151,215

Stirling's formula 110,244

sum and maximum properties 82,93

sum-convolution 183,185

Tuan's generalization of the H-transform 132

Whittaker function 152 


\section{This page is intentionally left blank}




\section{NOTATIONS}

$$
\begin{aligned}
& \text { (a) } 1,103 \\
& B(s, t) 193 \\
& C_{n}^{k} 238 \\
& \left(\begin{array}{l}
\alpha \\
n
\end{array}\right) 239 \\
& \left(c^{*}, \gamma^{*}\right) 143 \\
& f^{*} \text { (s) } 119,120,121 \\
& (f * g)(x) \quad 162,170 \\
& \text { L } \\
& (f * g)(x) 163 \\
& (f * g)+(x) \quad 183,185 \\
& (f * g)_{\text {max }}(x) 186 \\
& I(\alpha, \beta) \\
& \text { (f*g) (x) } 211 \\
& \mathrm{~K} v \\
& (f * g)(x) 214 \\
& \mathrm{~s}_{\alpha} \\
& (f * g)(x) 216 \\
& J(\alpha, \beta) \\
& (f * g)(x) 221 \\
& \begin{array}{l}
\text { sin } \\
(f * g)(x) \quad 225
\end{array} \\
& { }_{(f * g)_{(\lambda, \omega)}(x) 225} \\
& \mathrm{~F}\left[\mathrm{x}, \mathrm{y} ;(\alpha, \mathrm{a}, \mathrm{A})_{\mathrm{m}} ;(\beta, \mathrm{b}, \mathrm{B})_{\mathrm{n}}\right] 59 \\
& F_{1}\left(\alpha, \beta, \beta^{\prime} ; \gamma ;-x,-y\right) \quad 44,113
\end{aligned}
$$


$F_{2}\left(\alpha, \beta, \beta^{\prime} ; \gamma, \gamma^{\prime} ;-x,-y\right) \quad 44,115$

$F_{3}\left(\alpha, \alpha^{\prime} ; \beta, \beta^{\prime} ; \gamma ;-x,-y\right) 44,114$

$F_{4}\left(\alpha, \beta ; \gamma, \gamma^{\prime} ;-x,-y\right) \quad 44,114$

${ }_{1} F_{1}(a, b ; c ; z) 152$

${ }_{2} F_{1}(a, b ; c ; z) 1$

$\mathrm{p}_{\mathrm{q}}\left[\begin{array}{c}\mathrm{a}_{1}, \ldots, \mathrm{a}_{\mathrm{p} ;} \\ \mathrm{b}_{1}, \ldots, \mathrm{b}_{\mathrm{q}} ;\end{array}\right] 1$

$\left.F^{A: B ; B^{\prime}} \begin{array}{l}(a):(b) ;\left(b^{\prime}\right) ; \\ \text { C:D; } D^{\prime}(c):(d) ;\left(d^{\prime}\right) ;\end{array}\right) 4,103$

$G_{p, q}^{m, n}\left(z \mid \begin{array}{c}\left(\alpha_{p}\right) \\ \left(\beta_{q}\right)\end{array}\right) 2$

$G_{p, q}^{m, n}\left(\begin{array}{c}(\alpha)_{1, p} \\ (\beta)_{1, q}\end{array}\right) \circ[f(u)](x) 142$

$G\left[\begin{array}{l}x \\ y\end{array}\right] 5$

$G \underset{p_{1}, q_{1}: p_{2}, q_{2} ; p_{3}, q_{3}}{m_{1}, n_{1}: m_{2}, n_{2} ; m_{3}, n_{3}}\left(x, y \mid \begin{array}{ccc}\left(\alpha_{p_{1}}^{(1)}\right): & \left(\alpha_{p_{2}}^{(2)}\right) ; & \left(\alpha_{p_{3}}^{(3)}\right) \\ \left(\beta_{q_{1}}^{(1)}\right): & \left(\beta_{q_{2}}^{(2)}\right) ; & \left(\beta_{q_{3}}^{(3)}\right)\end{array}\right)$

$G_{1}\left(\alpha, \beta, \beta^{\prime} ; x, y\right) 65$

$H_{p, q}^{m, n}\left(x \mid \begin{array}{c}\left(\alpha_{p}, a_{p}\right) \\ \left(\beta_{q}, b_{q}\right)\end{array}\right) 3$ 


$$
\begin{aligned}
& H_{p, q}^{m, n}\left(\begin{array}{l}
(\alpha, a) \\
(\beta, b) \\
1, p
\end{array}\right) \circ[f(u)](x) 132 \\
& \mathrm{H}\left[\mathrm{x}, \mathrm{y} ; \quad(\alpha, \mathrm{a}, \mathrm{A})_{\mathrm{m}} ; \quad(\beta, \mathrm{b}, \mathrm{B})_{\mathrm{n}} ; \mathrm{L}_{\mathrm{s}}, \mathrm{L}_{\mathrm{t}}\right] 9 \\
& \mathrm{H}\left[\mathrm{x} ;(\alpha, \mathrm{a})_{\mathrm{m}} ;(\beta, \mathrm{b})_{\mathrm{n}} ; \mathrm{L}_{\mathrm{s}}\right] 9 \\
& H \underset{p_{1}, q_{1}: p_{2}, q_{2} ; p_{3}, q_{3}}{m_{1}, n_{1}: m_{2}, n_{2} ; m_{3}, n_{3}}\left(x, y \mid \begin{array}{c}
\left(\alpha_{p_{1}}^{(1)}, a_{p_{1}}^{(1)}\right):\left(\alpha_{p_{2}}^{(2)}, a_{p_{2}}^{(2)}\right) ;\left(\alpha_{p_{3}}^{(3)}, a_{p_{3}}^{(3)}\right) \\
\left(\beta_{q_{1}}^{(1)}, b_{q_{1}}^{(1)}\right):\left(\beta_{q_{2}}^{(2)}, b_{q_{2}}^{(2)}\right) ;\left(\beta_{q_{3}}^{(3)}, b_{q_{3}}^{(3)}\right)
\end{array}\right) 72 \\
& H_{3}(\alpha, \beta ; \gamma ;-x,-y) \quad 44,65 \\
& \mathrm{H}_{6}(\alpha ; \gamma ;-\mathrm{x},-\mathrm{y}) 46 \mathrm{H}_{7}(\alpha ; \gamma, \delta ;-\mathrm{x},-\mathrm{y}) 46 \\
& I_{ \pm}^{\alpha}\left(x^{-\alpha} f(x)\right) 147 \\
& \left\{J_{v}(2 \sqrt{x})\right\} \circ[f(u)] 148 \\
& \left\{\Gamma(\rho)(1+x)^{-\rho}\right\} \circ[f(u)] 151 \\
& \left\{2 K_{\nu}(2 \sqrt{x})\right\} \circ[f(u)] 151 \\
& \left\{\Gamma\left[\begin{array}{l}
a \\
b
\end{array}\right]_{1} F_{1}(a ; b ;-x)\right\} \circ[f(u)] 152 \\
& \left\{\Gamma[1 / 2-\rho-v, 1 / 2-\rho+v] e^{(2 x)^{-1}} W_{\rho, v}\left(\frac{1}{x}\right)\right\} \circ[f(u)] 152 \\
& \left\{x^{\alpha} k(x)\right\} \circ[f(u)] 145
\end{aligned}
$$


$\left\{x^{\alpha} k(x)\right\}^{-1} \circ[f(u)] 145$

$\left(x^{\alpha} \Lambda_{ \pm} x^{-\alpha}\right)(f(x)) 146$

$\left(x^{\alpha} \Lambda_{ \pm}^{-1} x^{-\alpha}\right)(f(x)) 146$

$\left(x^{\alpha} \Psi_{a}^{b} x^{-\alpha} f\right)(x) 235$

$\left(x^{\alpha} A l v^{-\alpha} f\right)(x) 235$

$\left(x^{\alpha} L_{k}^{\lambda} x^{-\alpha} f\right)(x) 235$

$\left(x^{\alpha}\left\{\frac{\Gamma(b)}{\Gamma(a)} F_{a}^{b}\right\}^{-1} x^{-\alpha} f\right)(x) 236$

$\left(x^{\alpha} F_{a, b}^{c} x^{-\alpha} f\right)(x) 236$

$\pi / f(x, y) ; s, t\}=f^{*}(s, t) 54$

$\mathrm{J}^{-1}$ (L) 120

$\mathrm{m}_{\mathrm{c}, \gamma}^{-1}(\mathrm{~L}) \quad 121$

$\mathrm{L}(\sigma) 120$

$L\left(\sigma_{s} \times \sigma_{t}\right) 164$

$L\left(x^{-1 / 2} ; 0, \infty\right) 185$

$\mathrm{L}_{c}, \mathrm{~L}_{\mathrm{C}} 52$

$\mathrm{L}_{\mathrm{s}}, \mathrm{L}_{\mathrm{t}} 9,10$

(Lf) (x) 163

(Sf)(x) 220

$\left\{\frac{1}{\sqrt{\pi}} \sin (2 \sqrt{x})\right\} \circ[f(u)] 149$ 


$$
\left\{\frac{1}{\sqrt{\pi}} \cos (2 \sqrt{x})\right\} \circ[f(u)] 149
$$

$$
\Gamma\left[\begin{array}{c}
\alpha_{1}, \ldots, \alpha_{p} \\
\beta_{1}, \ldots, \beta_{q}
\end{array}\right] \quad 43,106
$$

$$
H_{4}(\alpha, \beta ; \gamma, \delta ;-x,-y) 44
$$$$
\Phi_{1}(\alpha, \beta ; \gamma ;-x,-y) 45
$$$$
\Phi_{2}\left(\beta, \beta^{\prime} ; \gamma ;-x,-y\right) 45
$$$$
\Phi_{3}(\beta ; \gamma ;-x,-y) 45
$$$$
\Psi_{1}\left(\alpha, \beta ; \gamma, \gamma^{\prime} ;-x,-y\right) 45
$$$$
\Psi_{2}\left(\alpha, \gamma, \gamma^{\prime} ;-x,-y\right) 46
$$$$
\Xi_{1}\left(\alpha, \alpha^{\prime}, \beta ; \gamma ;-x,-y\right) 46
$$$$
\Xi_{2}(\alpha, \beta ; \gamma ;-x,-y) 46
$$

$$
(\kappa, \mu) \quad 133,190
$$$$
\theta(\tau) \quad 8,9
$$$$
\Phi(\tau) 3
$$$$
\Psi(\tau) 2
$$

$\sigma 120$ 